\title{
Research Development on Extracting of Aluminum from the Fly ash by Roasting Acid Leaching

\author{
Xiujun SUN
}

\author{
Department of Environmental and Chemical Engineering, Tangshan College, Tangshan 063000, \\ China
}

email: sunxiujun521@126.com

\section{Keywords: Fly Ash; Acid Leach; Dissolution Rate}

\begin{abstract}
The conditions of roasting activation of fly ash with $\mathrm{NaF}$ as assistant and extraction of $\mathrm{Al}_{2} \mathrm{O}_{3}$ by acid leaching were studied. The effects of conditions of roasting activation and acid leaching on the leaching rate of aluminum from fly ash were investigated of the pre- and post-extracted fly ash were analyzed by SEM.The results show that the optimal conditions of roasting activations were obtained as:mass ratio of coal fly ash to $\mathrm{NaF} 5: 1$, under time 60 min,temperature $850^{\circ} \mathrm{C}$; the optimal conditions of leaching temperature $80^{\circ} \mathrm{C}$, leaching time $120 \mathrm{~min}$, concentration of $\mathrm{H}_{2} \mathrm{SO}_{4} 1.2 \mathrm{~mol} / \mathrm{L}$, liquid-to-solid ratio $12 \mathrm{~mL} / \mathrm{g}$, the dissolution rate of aluminum reached 94.1\%. The preparation of $\mathrm{Al}_{2} \mathrm{O}_{3}$ was obtained after edulcoration and production.
\end{abstract}

\section{Introduction}

It has always been an important problem needed to be solved urgently to utilize fly ash comprehensively.At this moment, the main application of fly ash in domestic and oversea are concentrate on the aspects of industries of building and transportation and so on, which is low value-added exploit, with low use ratio. Therefore the future direction of utilization technology of fly ash is to improve the use ratio of fly ash and develop product of high additional value. Fly ash contains a large number of valuable elements,mainly are silicon and aluminum, especially the content of aluminum oxide, which can be a good alternative of bauxite, is as high as $30 \%-45 \%$ the highest purity may reach to 50 percent.In The Comprehensive Utilization Of Fly Ash Management Approach that has just been revised and was put into effective in 1st of March, 2013, there are a serial of specific encouraging policies to develop the technology to extract alumina oxide and related products that processes high added value.Accordingly, there is encouraging future to study the law of sulfide of aluminum oxide .

The process of extracting aluminum oxide from fly ash has been studied by both institutions in domestic and oversea, mainly are methods of alkali sintering and acid leading.Among them, acid leading method is the prime choice of comprehensive fly ash utilization.

\section{Experimental}

\subsection{Agentia,Material and Instrument}

Cup Chemical materials: $\mathrm{NaF}, \mathrm{H}_{2} \mathrm{SO}_{4}$ (analytical grade) . The coal fly ash was obtained from a thermal power plant in Shanxi, China. Chemical composition of coal fly ash was shown in Table1. The total content of $\mathrm{SiO}_{2}, \mathrm{Al}_{2} \mathrm{O}_{3}$ and $\mathrm{Fe}_{2} \mathrm{O}_{3}$ reached above $87 \%$.

Tab.1Chemical composition of coal fly ash $(\%, \omega)$

\begin{tabular}{ccccccccc}
\hline $\begin{array}{c}\text { Chemical } \\
\text { component }\end{array}$ & $\mathrm{SiO}_{2}$ & $\mathrm{Al}_{2} \mathrm{O}_{3}$ & $\mathrm{CaO}$ & $\mathrm{MgO}$ & $\mathrm{TiO}_{2}$ & $\mathrm{Fe}_{2} \mathrm{O}_{3}$ & $\begin{array}{c}\text { Loss on } \\
\text { ignition }\end{array}$ & $\begin{array}{c}\text { Integral } \\
\text { dose }\end{array}$ \\
\hline $\begin{array}{c}\text { Chemical } \\
\text { constitution }\end{array}$ & 43.28 & 39.00 & 1.30 & 1.15 & 0.65 & 5.43 & 8.90 & 99.56 \\
\hline
\end{tabular}

The SEM in Figure 1 shows that fly ash contains a lot of needle like or rod like morphology of mullite crystal, and major aluminum silicate vitreous spherical. 


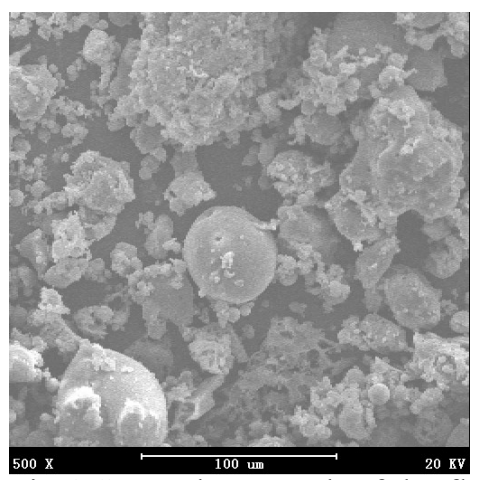

Fig.1 SEM photograph of the fly ash

Main instruments: HH-4 type digital constant temperature water bath pot, SHB-3 type circulating water vacuum pump, the type 722 visible light spectrophotometer, DHG-9070A type a thermostatic drum wind drying oven

\subsection{Experiment design}

Two key steps of extracting aluminum oxide are the process of calcination and acid leaching.

Calcination: weigh a certain amount of fly ash calcination, add the calcining additive $\mathrm{NaF}$, mix evenly, put them in a silver crucible, and placed in calcination in a muffle furnace. The calcination temperature range is $500-1000^{\circ} \mathrm{C}$. After a certain of calcination time, take out and cool to room temperature. The samples of acid leaching were obtained.

Acid leaching: calcined product was ground and sieved to 200 mesh size. Acid leaching experiments were done in the constant temperature water-bath water (500 $\mathrm{ml}$ three-necked flask was used for leaching container), and were mixed in a flask with agitation equipment. To prevent acid volatile and moisture evaporation, three-necked bottles were needed to connect condenser device). Under the condition of considering four influencing factors, the pickling time, acid concentration, solid-liquid ratio, reaction temperature and so on, sulphuric acid condenser device was applied to dissolve out of $\mathrm{Al}_{2} \mathrm{O}_{3}$. After reaction fully, impurity was removed, products were made into $\mathrm{Al}_{2} \mathrm{O}_{3}$ powders preparation stage.

\subsection{Analytic method}

The measurement of each component in fly ash adapts GBT 1574-2007 component analysis of coal fly ash.

\section{The Experiment Result and the Discussion to It}

\subsection{Activation of Fly Ash and Factor Analysis Influencing it}

Aluminum oxide and silicon exist in fly ash in the form of complicated double salt aluminum vitreous and alusite, whose acid solubility is extremely poor, for it need powerful energy to break the silicon and aluminum key to transform from stable aluminum to mineral substance soluble to acid. Take calcination time, temperature and dosage of activator as impact factors, the orthogonal experiment was designed to conduct with three different amount. To ensure better condition for process of calcination and activation, the parameter of acidleach should be fixed in: temperature: $80^{\circ} \mathrm{C}$; concentration of $\mathrm{H}_{2} \mathrm{SO}_{4}, 1.2 \mathrm{~mol} / \mathrm{L}$;liquid-solid ratio, 20:1（ml: $\mathrm{g}$ ）.

Result can be represented as Chart 2, from the experiment designed according to orthogonal table. It can be seen that the three factors impacting fly ash activation are calcination temperature, the ratio of Fly Ash between $\mathrm{NaF}$ in fly ash and calcination time in sequence according to the importance. It is acknowledged from Analysis of Means that optimum condition for activation calcination is to maintain the temperature at $850{ }^{\circ} \mathrm{C}$, the ratio between Fly Ash and NaF being 20:4 and keep calcination time 120min.

Factor analysis shows that the longer calcination time is, the higher dissolution rate of $\mathrm{Al}_{2} \mathrm{O}_{3}$ will be. But taking practical reasons into account, calcination time is designed as 60 min since that calcination time impacts activation less obviously, thus the preferred process condition for 
activation calcination is to maintain the temperature at $850{ }^{\circ} \mathrm{C}$, the ratio between Fly Ash and $\mathrm{NaF}$ being 20:4 and keep calcination time $60 \mathrm{~min}$.

Tab.2 The result of orthogonal experiments

\begin{tabular}{ccccc}
\hline $\begin{array}{c}\text { Numb } \\
\text { er }\end{array}$ & $\begin{array}{c}\text { Calcination } \\
\text { time } \\
(\min )\end{array}$ & $\begin{array}{c}\text { Calcination } \\
\text { temperation } \\
\left({ }^{\circ} \mathrm{C}\right)\end{array}$ & $\begin{array}{c}\text { Caol ash/NaF } \\
(\omega)\end{array}$ & $\begin{array}{c}\mathrm{Al}_{2} \mathrm{O}_{3} \text { solubility } \\
(\%)\end{array}$ \\
\hline 1 & 60 & 650 & $10: 1$ & 61.91 \\
2 & 60 & 750 & $10: 1.5$ & 81.72 \\
3 & 60 & 850 & $10: 2$ & 96.10 \\
4 & 90 & 650 & $10: 1.5$ & 74.81 \\
5 & 90 & 750 & $10: 2$ & 89.70 \\
6 & 90 & 850 & $10: 1$ & 79.99 \\
7 & 120 & 650 & $10: 2$ & 80.81 \\
8 & 120 & 750 & $10: 1$ & 73.21 \\
9 & 120 & 850 & $10: 1.5$ & - \\
mean1 & 79.910 & 72.510 & 72.000 & - \\
mean 2 & 81.797 & 81.543 & 81.927 & - \\
mean3 & 82.090 & 89.743 & 88.870 & - \\
range & 2.190 & 17.273 & 16.890 & - \\
\hline
\end{tabular}

\subsection{Acid Leaching of Coal Ash and Factor Analysis Influencing It}

The experiment has studied key factors affecting dissolution rate of $\mathrm{Al}_{2} \mathrm{O}_{3}$ such as temperature of acidleach, time of acidleach, concentration of $\mathrm{H}_{2} \mathrm{SO}_{4}$ and ratio of solid and liquor, adapting the method of with one single factor changed and other fixed.

\subsubsection{Influence of Temperature to Dissolution Rate of Al2O3}

Fixed experiment condition is setting acid leaching time as $120 \mathrm{~min}$, concentration of $\mathrm{H}_{2} \mathrm{SO}_{4}$ as $1.2 \mathrm{~mol} / \mathrm{L}$ and ratio of solid and liquor as 20:1. Given the demand of low energy of experiment, the experiment conducting six single factor analysis in the temperature below $100^{\circ} \mathrm{C}$, obtains the result as following graph.

Tab.3 Influence of the temperature to alumina dissolving ratio

\begin{tabular}{ccccccc}
\hline Temperature $/{ }^{\circ} \mathrm{C}$ & 50 & 60 & 70 & 80 & 90 & 100 \\
\hline Dissolving ratio/\% & 66.1 & 79.8 & 89.9 & 94.1 & 94.5 & 94.6 \\
\hline
\end{tabular}

Tab.3 shows that, as the increase of reaction temperature, the dissolving ratio rises, too, because with the temperature rises, the move speed of molecule adds, viscosity of solution decrease and diffusivity increases hence lead to accelerate reaction speed. The change will be more obvious in the temperature of $50^{\circ} \mathrm{C} \sim 80^{\circ} \mathrm{C}$. When temperature is above $80^{\circ} \mathrm{C}$, there are still the rising trend of dissolving ratio, while a slow one. Considering to decrease energy consuming, the suitable temperature is $80^{\circ} \mathrm{C}$.

\subsubsection{The Influence of Time of Acid Leaching to Dissolving Ratio of Al3O2}

Fixed experiment condition is setting acid leaching temperature as $80^{\circ} \mathrm{C}$, concentration of $\mathrm{H}_{2} \mathrm{SO}_{4}$ as $1.2 \mathrm{~mol} / \mathrm{L}$ and ratio of solid and liquor as $20: 1$. The result of experiment changing acid leaching time as single factor is demonstrated as Tab.4.

Tab.4 I Influence of the time treated by $\mathrm{H}_{2} \mathrm{SO}_{4}$ to alumina dissolving ratio

\begin{tabular}{ccccccc}
\hline Time $/ \mathrm{min}$ & 30 & 60 & 90 & 120 & 150 & 180 \\
\hline Dissolving ratio/\% & 76.8 & 85.0 & 94.1 & 94.1 & 94.1 & 94.3 \\
\hline
\end{tabular}


It can be learned that with the increase of acid leaching time, the alumina dissolving ratio rises constantly. And it would be up to maximum when the leaching time is 120 minutes. While aluminum oxide dissolution rate was not significantly increase as it continued to increase the reaction time. That is because at reaction initial stage, sulfuric acid was in high concentration, the reaction product layer was not completely healed, the activity site of the solid reaction can be sufficiently in contact with the sulfuric acid, and then the dissolution rate of aluminum increased substantially. As the reaction proceeded, the reaction interface healed, the rate of inner diffusion slowed, the concentration of sulfuric acid was reduced, therefore, the dissolution rate would not substantially increase even if the time was extended ${ }^{[7]}$. The extension of acid leaching time would result in losses of equipment and energy, and therefore 120min was chosen for leaching time.

\subsubsection{The Influence of the Concentration of Sulfuric Acid to Dissolving Ratio of A12O3}

Owing to the strong oxidized characteristic of the sulfuric acid,the chemical reaction will be more intense than hydrochloric acid.

Fixing experiment condition is setting leaching time as 120 minutes and ratio of solid and liquor as 20:1.The result of experiment changing concentration of sulfuric acid is demonstrated as Tab.5 .

Tab.5 Influence of the time treated by $\mathrm{H}_{2} \mathrm{SO}_{4}$ to alumina dissolving ratio

\begin{tabular}{ccccccc}
\hline $\mathrm{H}_{2} \mathrm{SO}_{4} / \mathrm{mol} / \mathrm{L}$ & 0.6 & 0.9 & 1.2 & 1.5 & 1.8 & 2.1 \\
\hline $\begin{array}{l}\text { Dissolving } \\
\text { ratio/\% }\end{array}$ & 75.8 & 85.0 & 94.1 & 94.2 & 94.3 & 94.0 \\
\hline
\end{tabular}

Tab.5 shows that,with increase of sulphuric acid concentration, the dissolving ratio rises. As the concentration of sulfuric acid is up to $1.5 \mathrm{~mol} / \mathrm{L}$, the dissolving ratio is up to $96 \%$. However the dissolving ratio would reduce as the concentration of sulfuric acid continues to increase. This is because as the increase of the oxidizing property of solution, the dissolving ratio would rise if the concentration of sulfuric acid is less than $1.5 \mathrm{~mol} / \mathrm{L}$. And if sulphuric acid concentration is more than $1.5 \mathrm{~mol} / \mathrm{L}$,part of the aluminum sulfate in the form of crystal exists in filter residue which result in the decrease of the dissolving ratio.aluminum oxide dissolution rate was not significantly increase as the concentration of sulfuric acid is from $1.2 \mathrm{~mol} / \mathrm{L}$ to $1.5 \mathrm{~mol} / \mathrm{L}$. Thus considering to decrease energy consuming , the suitable sulphuric acid concentration is $1.2 \mathrm{~mol} / \mathrm{L}$.

\subsubsection{The Influence of Ratio of Solid and Liquor to Dissolving Ratio of Al2O3}

Fixed experiment condition is setting leaching temperature as 80 centigrade and concentration of $\mathrm{H}_{2} \mathrm{SO}_{4}$ as $1.2 \mathrm{~mol} / \mathrm{L}$. The result of experiment changing ratio of solid and liquor as single factor is demonstrated as Tab.6.

Tab.6 Influence of $\mathrm{NaF} /$ ash ratio to alumina dissolving ratio

\begin{tabular}{lcccccc}
\hline $\mathrm{L}: \mathrm{S} / \mathrm{mL} / \mathrm{g}$ & 0.6 & 0.9 & 1.2 & 1.5 & 1.8 & 2.1 \\
\hline $\begin{array}{l}\text { Dissolving } \\
\text { ratio/\% }\end{array}$ & 75.8 & 85.0 & 94.1 & 94.2 & 94.3 & 94.0 \\
\hline
\end{tabular}

Tab.6 shows that,as the increase of the ratio of liquid-solid ,the speed of dissolving ratio rises when the ratio of liquid-solid is less than 12.As the ratio of liquid-solid is more than 12, the increase trend of dissolving ratio become slower.This is because as the increase of the ratio of liquid-solid,the solid-liquid interface increases which lead to the the rises of dissolving ratio.Considering to decrease energy consuming, the suitable ratio of liquid-solid is about 12:1. 


\subsection{Characteristics of fly ash and fly ash after acid leaching}

The SEM(scanning electron microscope)morphologies of the pre-and post-extracted fly ash

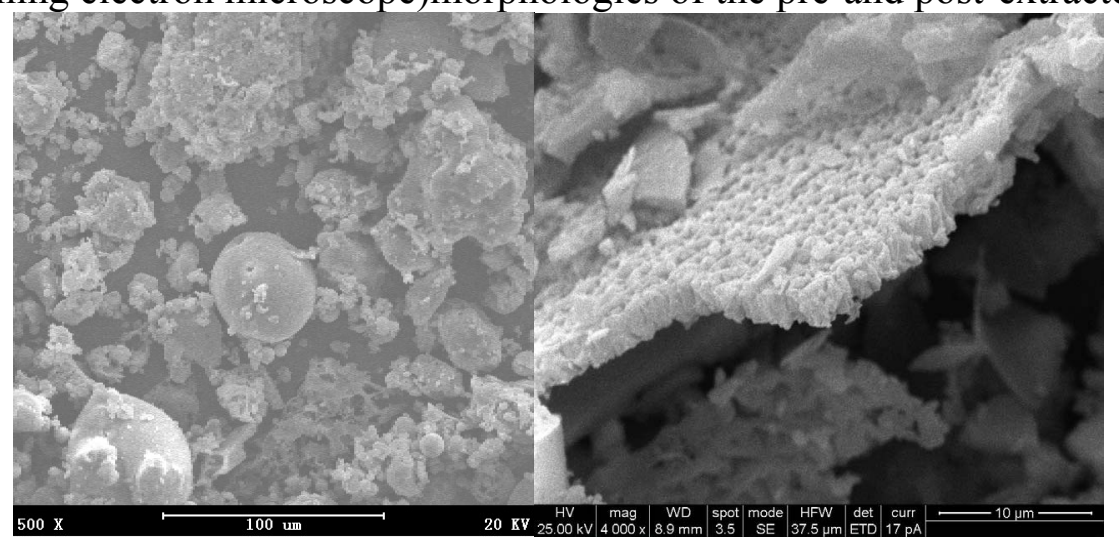

Fig 2 SEM morphologies of the pre- and post-extracted fly ash

Picture 6 indicates the morphology of fly ash changes a lot, the previous morphology, approximate sphere were destructed and formed nearly flake structure with high porosity in surface.

\subsection{Product of Extraction and Manufacture}

Through the reaction of acid leach, the alumina dissolving rate can reach to $94.1 \%$, but elements in fly ash like $\mathrm{Si}, \mathrm{F}, \mathrm{Ti}, \mathrm{Ca}$ and $\mathrm{Mg}$ have to be dissolved too in the meantime to ensure acquiring high quality alumina product by procedure of extraction and manufacture.

$\mathrm{pH}$ value of aluminum and iron complete precipitation was lower compared with that of other oxides, so it was considered that the $\mathrm{pH}$ range was controlled in order to remove iron. Sodium hydroxide solid was added to adjust $\mathrm{pH}$ value between 5-6, and then it was filtered to precipitate aluminum and iron, $8 \mathrm{~mol} / \mathrm{L} \mathrm{NaOH}$ solution was added in the coprecipitation of aluminum and iron, the $\mathrm{pH}$ was adjusted between $12-12.5$, then $\mathrm{Al}(\mathrm{OH})_{3}$ precipitation was completely dissolved and $\mathrm{NaAl}(\mathrm{OH})_{4}$ was generated, the iron was removed by filtration, and finally washed, iron precipitation was dried, iron was effectively recovered.

The obtained $\mathrm{NaAl}(\mathrm{OH})_{4}$ solution by reaction consisted a bit of $\mathrm{SiO}_{2}$ and $\mathrm{Na}_{2} \mathrm{SiO}_{3}$. The essence of sodium aluminosilicate solution desilication process is that $\mathrm{SiO}_{2}$ was changed into compounds of small solubility. Saturated lime water could be added to the solution by using the method of depth desilication. An amount of lime was added so that $\mathrm{SiO}_{2}$ was formed into garnet hydrate precipitation. $\mathrm{CO}_{2}$ gas was bubbled into sodium aluminate solution through deep desilication for carbonation, and aluminum hydroxide precipitation was obtained. The precipitate was filtered, washed, ashed and heated $60 \mathrm{~min}$ for dehydration in a muffle furnace at the temperature of $230^{\circ} \mathrm{C}$. $\mathrm{Al}(\mathrm{OH})_{3}$ product was obtained. The product was heated to $800^{\circ} \mathrm{C}$ and continued calcined for $2 \mathrm{~h}$. Their chemical composition were analyzed (table7). The products met the requirements of metallurgical grade alumina and national secondary $\mathrm{Al}_{2} \mathrm{O}_{3}$ standard.

Tab.7 Chemical composition of $\mathrm{Al}_{2} \mathrm{O}_{3}(\%, \omega)$

\begin{tabular}{ccccc}
\hline Composition & $\mathrm{Al}_{2} \mathrm{O}_{3}$ & $\mathrm{SiO}_{2}$ & $\mathrm{Fe}_{2} \mathrm{O}_{3}$ & Integral dose \\
\hline Content & 99.15 & 0.03 & 0.002 & 99.182 \\
\hline
\end{tabular}

\section{Conclusion}

Using $\mathrm{NaF}$ as auxiliaries to calcine and active fly ash, the orthogonality represents that factors impacting fly ash activation are calcination temperature, the ratio of Fly Ash between $\mathrm{NaF}$ in fly ash and calcination time in sequence according to the importance;Utilizing $\mathrm{H}_{2} \mathrm{SO}_{4}$ to dissolve fly ash, single-factor experiment indicates that :with the condition of temperature in $80^{\circ} \mathrm{C}$,concentration of $\mathrm{H}_{2} \mathrm{SO}_{4}, 1.2 \mathrm{~mol} / \mathrm{L}$; liquid-solid ratio being $12: 1$, alumina dissolving ratio can reach $94.1 \%$; The 
morphology of fly ash changes a lot, from approximate sphere to flake structure with high porosity in surface.

\section{Acknowledgement}

In this paper, the research was sponsored by the Young Foundation Projecet in the Department of Education of Hebei Province (Project No. QN2015302) and Key Laboratory of Fine Chemical of Tangshan (Project No. 140080109).

\section{References}

[1] Yansheng Deng, Sujuan Xu, Tan Jun, Tang Min.New Technology of Comprehensive Utilization of Fly Ash[J].Inorganic Salt Process, 2009,41 (9) :50-53

[2] Chuanda Xu,Fang Ying,Li Zhen,Ji Tao.Research progress in extracting silica from fly ash[J].New Chemical Material, 2013,43 (3):158-160

[3] Peimei Sun,Guangmin Li.Study on sintering process of raw materials in extracting alumina from fly ash of coal industry power plate[J].Journal of China Coal Society, 2007,32 (7): 744-746.

[4]Xiujun Sun,Xinqian Shu.The study of extract aluminum from the fly ash with acid dissolution[J].Inorganic Salt Process, 2013, 45 (11) : 44 46.

[5]Junmei Zhao,Jinshan Zhang, Lixiaoxue, Experimental study on aluminum sulfate from fly ash sulfating roasting[J].Light Metal, 2014 (1):14 16

[6] Siqiong Li, Chen Jie.Research development on extracting alumina from fly ash[J].Light Metal, 2013 (11): 25 26.

[7] Genkuan Ren.Technology process of extraction of aluminum oxide and iron from fly a sh by acid leaching[J].Light Metal, 2011 (7) : 27 30 